\title{
Feature Selection of the Combination of Porous Trabecular with Anthropometric Features for Osteoporosis Screening
}

\author{
Enny I Sela*, Sri Hartati*, Agus Harjoko, Retantyo Wardoyo*, M Mudjosemedi** \\ *Department of Computer Science and Electronics, Universitas Gadjah Mada, Yogyakarta, Indonesia. \\ ** Department of Dentomaxillofacial Radiology, Universitas Gadjah Mada, Yogyakarta, Indonesia.
}

\begin{tabular}{l} 
Article Info \\
\hline Article history: \\
ReceivedOct 19, 2014 \\
Revised Dec 4, 2014 \\
Accepted Dec 26, 2014 \\
\hline
\end{tabular}

Keyword:

Anthropometric features Dental periapical X-Ray Osteoporosis Porous extraction

\begin{abstract}
This study aims to select the important features from the combination of porous trabecular pattern with anthropometric features for osteoporosis screening. The study sample has their bone mineral density (BMD) measured at the proximal femur/lumbar spine using dual-energy X-ray absorptiometry (DXA). Morphological porous features such as porosity, the size of porous, and the orientation of porous are obtained from each dental radiograph using digital image processing. The anthropometric features considered are age, height, weight, and body mass index (BMI). Decision tree (J.48 method) is used to evaluate the accuracy of morphological porous and anthropometric features for selection data. The study shows that the most important feature is age and the considered features for osteoporosis screening are porosity, vertical pore, and oblique pore. The decision tree has considerably high accuracy, sensitivity, and specificity.
\end{abstract}

Copyright @ 2015Institute of Advanced Engineering and Science. All rights reserved.

\section{Corresponding Author:}

Enny Itje Sela

Department of Computer Science and Electronics, Universitas Gadjah Mada, Yogyakarta, Indonesia Email: ennysela@akakom.ac.id

\section{INTRODUCTION}

Osteoporosis, a common metabolic disease characterizes by reduced bone mass and thinning of the trabecular microarchitecture, frequently results in fractures of vertebrae, hip, or forearm. There is a consensus that BMD should be used for operational definition of the degree of osteoporosis. Measurement BMD is the principal method of diagnosis of osteoporosis because patients with low BMD values have elevated risk of developing a bone fracture. DXA is the standard technique for determining BMD. However, BMD testing using DXA for all postmenopausal women is not practical. Because of the relative high cost and limited availability of DXA equipment, DXA cannot detect microstructure of bone architecture, which is the key to bone quality [1].

To overcome these problems, many studies have developed methods to assess bone quality using microstructure of bone architecture indicators. It has been demonstrated that trabecular bone pattern changing of the mandible may be associated with skeletal low BMD or osteoporosis. It implies that the possibility that trabecular bone pattern of the mandible detected on periapical dental radiographs may be useful indicator for identifying women with low skeletal BMD [2] [3]. Periapical radiographs are relatively inexpensive and are frequently taken in dental offices as an aid to diagnosis [3]. Since the trabecular bone can be easily visualized in periapical radiographs, many important information about the bone's condition on microstructure level can be extracted. On the trabecular bone, it can be extracted the trabecular segments (rods) and it's porous (plates). Bone strength is also determined from the porous structure property such as porosity, homogeneity, and anisotropy [4]. According [5], one of the suspicion of osteoporosis can be enforced if the pore in the lower jaw looks a little, irregular, and low connectivity.

There is a growing consensus that screening for osteoporosis should include anthropometric and clinical features such as age, height, weight, calcium intake, exercise and smoking habits [6]. Recently, there 
have been reported linking osteoporosis to combining trabecular segments with anthropometric and clinical features [2][3][6]. It is not known the important features on the combination of porous trabecular pattern with anthropometric features for osteoporosis screening. Accordingly, the purpose of this study selected features from the radiographic of porous trabecular pattern and the anthropometric features.Feature selection improves classification by searching for the subset of features, which best classify the training data [7].

\section{RESEARCH METHOD}

All periapical X-Ray images and anthropometric features were collected from the Department of Dentomaxillofacial Radiology of Prof. Soedomo Dental Hospital, Faculty of Dentistry, Universitas Gadjah Mada. The anthropometric features for osteoporosis, such as: age, height, weight, hormonal condition, calcium intake, smoking habits, were obtained from a questionnaire. Then, BMI is represented by weight divided by square of height. The anthropometric features considered in this study were age (U), height (TB), weight (BB), and BMI. Assessment of BMD and lumbar spine collected from the Department of Radiology Dr. Sardjito Hospital using DXA. Subjects were classified into one of three groups contained women who were classified according to the WHO classification: osteoporotic, osteopenia, and normal [3][6]. The overall model selects the important features from the combination of porous trabecular pattern with anthropometric features for osteoporosis screenin includes selection of ROIs, segmentation, porous feature extraction, selection of the features, decision tree visualization, and measuring performance to classify (Figure1). We will explain each of these in brief as below.

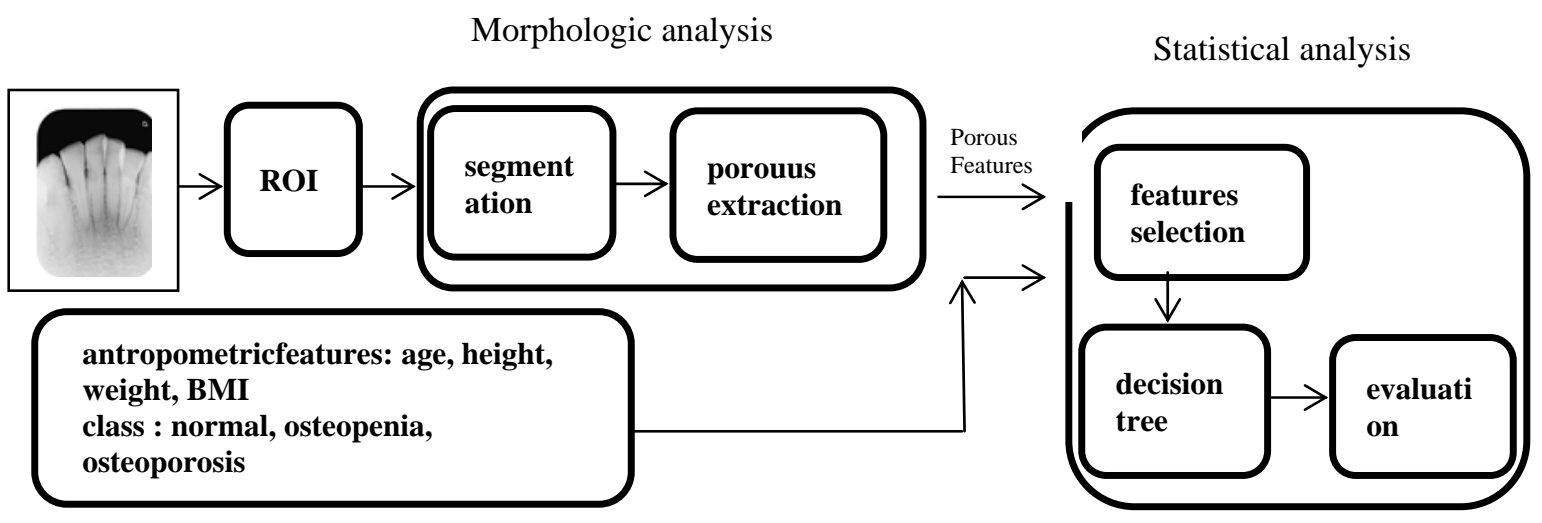

Figure 1. Feature selection model

An algorithm was developed to perform a sequential procedure to select region of interest (ROI) for each patient and segmentation on these ROIs [8]. The segmented images are processed to obtain porous features from each ROI using morphologic analysis. Porous features are then combined with anthropometric features to acquire a knowledge base in a decision tree. The decision tree shows the important features of the combination of porous and anthropometric features. The morphologic features that characterize the porous on a ROI are porosity, homogeneity, and the orientation of pore.

Porosity (Por) is ratio between porous area and total area on a ROI. The porous area is the total number of back pixel in binary image and total area on a ROI is the number of pixels on a ROI. Homogeneity can be represented by JK and JB. JK is ratio between the number of small pore and the total number of pore on a ROI while JB is ratio between the number of large pore and the total number of pore on a ROI. The small pore is the total number of pore which has area less than 72 pixels; the large pore is the total number of pore which has area more than and equal to 72 pixels [9]. On JK and JB features, labeling operation was used to obtain the number of pore in each ROI. The number of pore is the number of pore which have area 39 pixels or larger. There are three steps to obtain the orientation: find the centroid [10], find the orientation [11] and visualize the orientation. The orientation of pore feature is represented by $\mathrm{V}, \mathrm{H}$, and $\mathrm{O}$. $\mathrm{V}$ is ratio between the number of vertical pore and the total number of pore on a ROI. $\mathrm{H}$ is ratio between the number of horizontal pore and the total number of pore on a ROI. $\mathrm{O}$ is ratio between the number of oblique pore and the total number of pore on a ROI.The final result is the porous features consisting of $\mathrm{P}, \mathrm{JB}, \mathrm{JK}, \mathrm{V}, \mathrm{H}$, and $\mathrm{M}$. These features are stored in a data for statistical analysis using the decision tree.

Decision tree (C4.5 or J.48 method) is used to classify porous and anthropometric features as belonging to normal, osteopenia, or osteoporotic. C4.5 algorithm is one of data classification algorithms with

Feature Selection of the Combination of Porous Trabecular with Anthropometric Features ... (Enny I Sela) 
decision technique which is popular and favored due to its advantages [12]. To perform decision tree, Weka software is used. The decision tree method employs a recursive algorithm. At the start, all of data are considered together at the root of a prediction tree. The data are split on the variable that results in the largest difference among the successive nodes. In each daughter node, variables are again examined to find the predictor that results in the best split among normal, osteopenia, or osteoporosis. Splitting continues until stopping criteria are reached or until further splitting node does not improve classification [13]. Terminal nodes ("leaves") are classified as normal, osteopenia, or osteoporosis.

\section{RESULTS AND ANALYSIS}

Morphological porous analysis performed on the images using the image processing software. Figure 2 demonstrates morphological porous analysis result based on our framework above. It shows morphological differentiation of our classification class (normal, osteopenia, and osteoporosis).

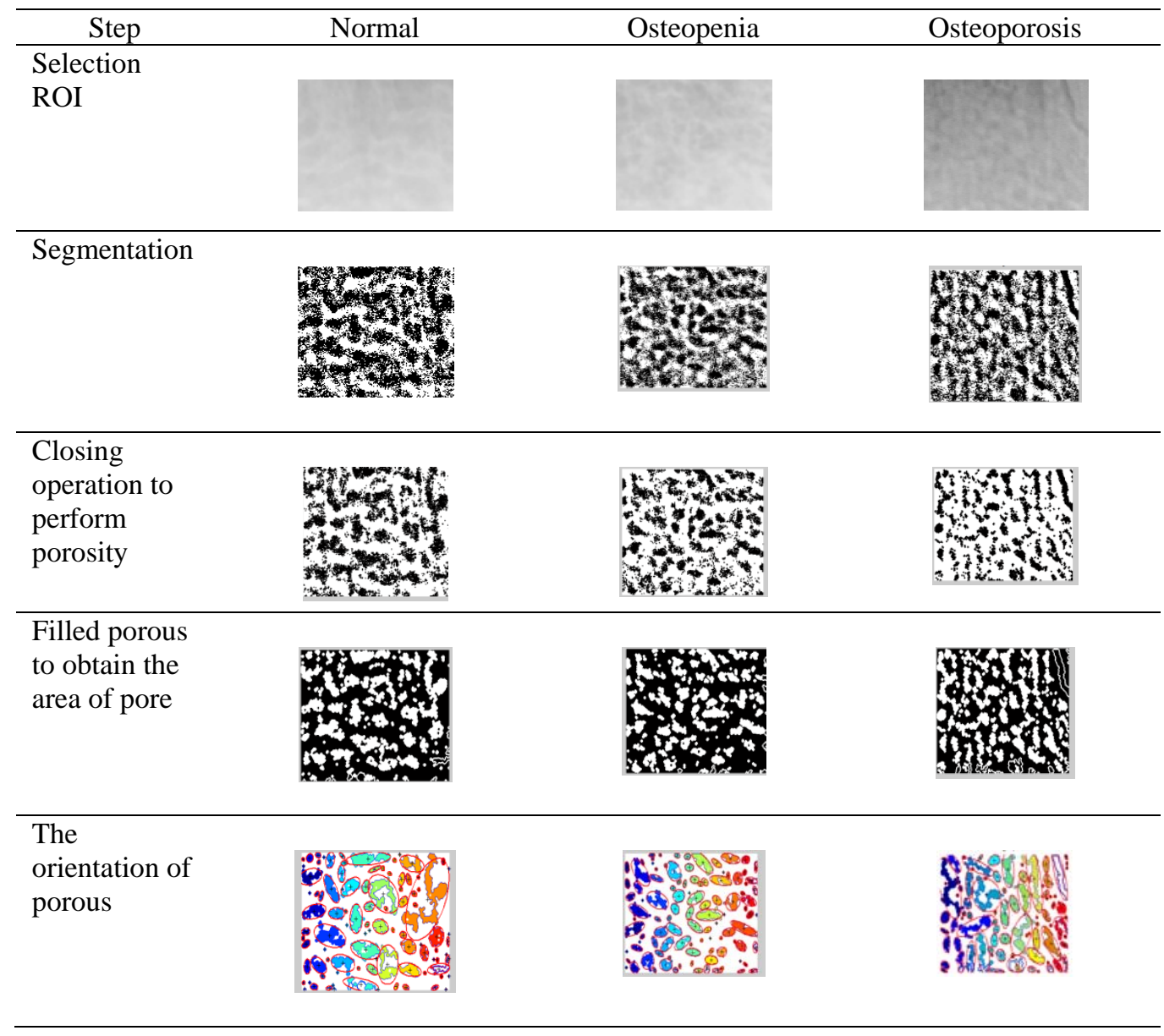

Figure 2. Morphologic Analysis

A decision tree analysis considering morphological porous and anthropometric features find that the important features for classifying data were U, Por, V, and M. as shown in Figure 3. The important anthropometric features were $\mathrm{U}$ and Por; the important morphologic features were $\mathrm{V}$ and $\mathrm{M}$. 


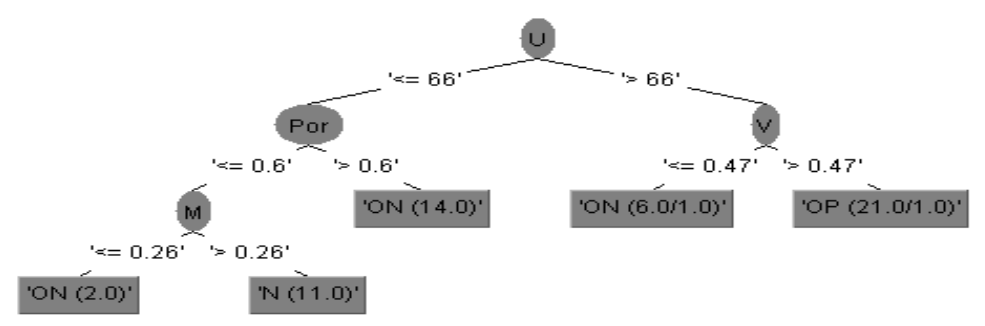

Figure3. Decision tree 9-fold cross-validation

Table 1 shows percentage accuracy, sensitivity, and specificity of decision tree testing for 9, 6, and 3 cross validation. It shows that this testing results the best evaluation for 9-cross validation test. This mode

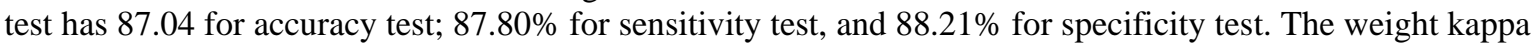
index, a measure of the agreement between the predicted and actual bone agreement, is 0.7982 .

Table 1. Percentage of accuracy, sensitifity, and spescificity test

\begin{tabular}{|c|c|c|c|c|c|}
\hline K-Fold & Accuracy(\%) & Kappa statistic & Class & Sensitivity (\%) & Specificity (\%) \\
\hline \multirow{4}{*}{9} & \multirow{4}{*}{87.04} & \multirow{4}{*}{0.7982} & Osteoporosis & 90.90 & 86.05 \\
\hline & & & Osteopenia & 77.27 & 96.77 \\
\hline & & & Normal & 95.24 & 81.81 \\
\hline & & & Average & 87.80 & 88.21 \\
\hline \multirow{4}{*}{6} & \multirow{4}{*}{87.04} & \multirow{4}{*}{0.7978} & Osteoporosis & 90.90 & 86.05 \\
\hline & & & Osteopenia & 90.48 & 87.5 \\
\hline & & & Normal & 85.71 & 87.88 \\
\hline & & & Average & 89.03 & 87.14 \\
\hline \multirow{4}{*}{3} & \multirow{4}{*}{83.33} & \multirow{4}{*}{0.7422} & Osteoporosis & 90.90 & 81.40 \\
\hline & & & Osteopenia & 68.18 & 93.75 \\
\hline & & & Normal & 95.24 & 75.75 \\
\hline & & & Average & 84.77 & 83.33 \\
\hline
\end{tabular}

The present study finds that the combination of age, height, weight, BMI and features of the porous of trabecular morphology of interdental bone is useful in identifying post-menopausal woman with low-bone mass. In this study, the age of subjects $(\mathrm{U})$ is considered to be the one of the most important feature for loss of bone mass. This finding is consistent with [3][6]. In addition, anthropometric features BMI was not important for identifying women with low BMD. It is not consistent with [3]. The important porous feature is porosity (Por), the oblique porous ( $\mathrm{M}$ ), and the vertical porous (V). The $\mathrm{M}$ and $\mathrm{V}$ features were consistent with [14] [15]. The Por feature is consistent with [7]. Several features (JK, JB, TB, and BB) have used in this study and they are not considered factors for osteoporosis. In this study, the anthropometric and radiographic features are analysis separately. The accuracy of anthropometric features and the radiographic features have a good testing with $\mathbf{8 0 . 3 3 \%}$ and $87.04 \%$ accuracy. This finding is not consistent with [3]. Table 2 shows this research can prove that features selection using C4.5 on the combination of porous andantropometic features results a significant value. 
Table 2. The comparison of results with other researchs

\begin{tabular}{|c|c|c|c|}
\hline Parameter & $\begin{array}{l}\text { Licks dkk } \\
\quad(2010)\end{array}$ & $\begin{array}{l}\text { Lee dan White } \\
\text { (2005) }\end{array}$ & This research \\
\hline $\begin{array}{l}\text { Method of decision } \\
\text { tree }\end{array}$ & $\begin{array}{l}\text { Classification and } \\
\text { Regression Tree Analysis } \\
(C A R T)\end{array}$ & $\begin{array}{l}\text { Classification and } \\
\text { Regression Tree } \\
\text { Analysis (CART) }\end{array}$ & $\begin{array}{l}\text { C4.5 } \\
\text { (3,6,9-fold validation) }\end{array}$ \\
\hline $\begin{array}{l}\text { Number of training } \\
\text { data }\end{array}$ & $\begin{array}{l}60 \text { (22 normal and } \\
\text { osteopenia; } 38 \\
\text { Osteoporosis) }\end{array}$ & 65 & $\begin{array}{l}54 \text { (11 normal, } 22 \\
\text { osteopenia, } 21 \\
\text { osteoporosis) }\end{array}$ \\
\hline $\begin{array}{l}\text { Number of testing } \\
\text { data }\end{array}$ & $\begin{array}{l}60 \text { (22 normal and } \\
\text { Osteopenia; } 38 \\
\text { Osteoporosis) }\end{array}$ & $\begin{array}{l}28 \text { (7 Normal, } 17 \\
\text { Osteopenia, } 4 \\
\text { Osteoporosis) }\end{array}$ & $\begin{array}{l}54 \text { (11 normal, } 22 \\
\text { osteopenia, } 21 \\
\text { osteoporosis) }\end{array}$ \\
\hline Testiing features & $\begin{array}{l}\text { Antropometric: height, } \\
\text { weight, BMI, age, } \\
\text { M1, M2, M3, M4 } \\
\text { M5, M6, M7, M8 } \\
\text { M9, M10, M11, } \\
\text { M12,M13, M14. }\end{array}$ & $\begin{array}{l}\text { Antropometric : } \\
\text { height, weight, BMI, } \\
\text { age, } \\
\text { Morphologic: } \\
\text { number of termini, } \\
\text { nodes per unit area, } \\
\text { number of length of } \\
\text { struts segment } \\
\text { between termini and } \\
\text { nodes. }\end{array}$ & $\begin{array}{l}\text { Antropometric : height, } \\
\text { weight, BMI, age, } \\
\text { Morphologic : por, JB, } \\
\text { JK, V, H, M }\end{array}$ \\
\hline $\begin{array}{l}\text { Gold-Standard } \\
\text { (classtarget) }\end{array}$ & $\begin{array}{l}\text { - lumbar/femoral BMD } \\
\text { DXA } \\
\text { - normal and } \\
\text { osteopenia/osteoporosis }\end{array}$ & $\begin{array}{l}\text {-lumbar/femoral } \\
\text { BMD DXA } \\
\text { - normal, } \\
\text { osteopenia, and } \\
\text { osteoporosis }\end{array}$ & $\begin{array}{l}\text {-lumbar/femoral BMD } \\
\text { DXA } \\
\text { - normal, osteopenia, and } \\
\text { osteoporosis }\end{array}$ \\
\hline $\begin{array}{l}\text { The most important } \\
\text { feature }\end{array}$ & age & age & Age \\
\hline $\begin{array}{l}\text { The considered } \\
\text { features }\end{array}$ & M8, M3, M12, BMI & Node:terminus ratio & Por, V, M \\
\hline Accuracy & $88.33 \%$ & $82 \%$ & $86.67 \%$ \\
\hline $\begin{array}{l}\text { Accuracy of } \\
\text { antropometic } \\
\text { features testing }\end{array}$ & - & & $80.33 \%$ \\
\hline $\begin{array}{l}\text { Accuracy of porous } \\
\text { features testing }\end{array}$ & - & - & $87.04 \%$ \\
\hline
\end{tabular}

M1: trabecular area / total area

M2: periphery / total area

M3: periphery / total area

M4: length / trabecular area

M5: length / total area

M6: terminal points / $\mathrm{cm} 2$

M7: terminal points / length
M8: terminal points / periphery

M9: terminal points / trabecular area

M10: branch points / cm2

M11: branch points / length

M12: branch points / periphery

M13: branch points / trabecular area

M14: branch points / terminal points

There are some limitations to design of this study. First, the sample size is modest, particularly in terms of the number of data with normal class. This study is not including male patients and it only took account of the subjects' age, weight, height, and BMI. Future studies should consider other anthropometric features for osteoporosis, such as exercise, smoking, or use of medications.

\section{CONCLUSION}

The study addressed the utility of trabecular porous features to contribute to the features selection of the the combination of porous trabecular pattern of the mandible with anthropometric features for osteoporosis screening with $87.04 \%$ accuracy. The selected features are $\mathrm{U}$, Por, $\mathrm{V}$, and $\mathrm{M}$. These features are capable for classifiying phase. 


\section{REFERENCES}

[1] Brandi, Maria L, 2009, Microarchiture, the key to bone quality, Rheumatology, 48:iv3-iv8, The Oxford University Press. DOI: 10.1093/rheumatology/kep273

[2] Asano A., Tambe T., Taguchi A., Asano CM., Nakamoto T., Tanimoto K., Hinamoto T. danMuneyasu M., 2006, Extraction of trabecular structures of mandible excluding tooth roots on dental panoramic radiographs using mathematical morphology, Proceeding The 18th International Conference on Pattern recognition (ICPR'06), Tokyo.

[3] Licks R., Licks V., Ourique F., Bittencourt H.R., Fontanella V., 2010, Development of prediction tool for low bone mass based on clinical data and periapical radiography, Dentomaxillofacial Radiology 39, 224-230, The British Institute of Radiology. DOI: $10.1259 / \mathrm{dmfr} / 23760876$

[4] Buie H.R., Campbell G.M., Klinck R.J., MacNeil Joshua A, Boyd S.K., 2007, Automatic segmentation of cortical and trabecular compartments based on a dual threshold technique for in vivo micro-CT bone analysis, Bone 4, 505515, Elsevier Inc. DOI: 10.1016/j.bone 2007.07.007

[5] Davison K.S. Josse H., Siminoski K., Adachi J.D., Hanley D.A., Goltzman D., Hodsman A.B., 2006, Bone Strength: The Whole is greater then the sum of its parts, Elsevier Inc. DOI; 10.1016/j.semarthrit 2006.04.002

[6] Lee B.D., and White S.C, 2005, Age and trabecular features of alveolar bone associated with osteoporosis, Oral Surg Oral Med Oral Pathol Oral RadiolEndod 2005; 100:92-8. DOI: 10.1016/j.tripleo 2004.11.020

[7] Hlaing, Thuzar, 2012, Feature Selection and Fuzzy Decision Tree for Network Intrusion Detection, International Journal of Informatics and Communication Technology (IJ-ICT) 1(2):109 118.DOI: 10.11591/ij-ict.v1i2.591

[8] Sela E.I., Hartati S., Harjoko A., Wardoyo R., Mudjosemedi M., 2013, Segmentation on the dental periapical X-Ray images for osteoporosis screening, Intl Journal of Advanced Computer Science and Application,4(7): 147-151.

[9] Padilla F., 2005, Influence of the precision of spectral backscatter measurements on the estimation of stutterers size in cancellous bone, Bone Quantitative Ultrasound, pp 123-14, Springer.

[10] Stojmenovic, Milos and Nayak, Amiya, 2007, Direct ellipse fitting and measuring based on shape boundaries, Advances in Image and Video Technology Lecture Notes in Computer Science 4872: 221-235, Springer

[11] Asatryan D., Egiazarian K., Kurkchiyan, 2010, Orientation Estimation with Applications to Image Analysis and Registration, International Journal Information Theories and Applications, 17(4): 303-311.

[12] Sudarma M and Hostiadi, The Establishment of Decision Tree Model in Network Traffic Incident Using C4.5 Method, International Journal of Informatics and Communication Technology (IJ-ICT) 3(1):23 29.DOI: 10.11591/ij-ict.v3i1.5179

[13] Han J. and Kamber., M., 2001, Data mining concepts and technique, Academic Press, USA

[14] Fields J.A., Lee G.L., Liu X.S., Jekir M.G., Guo X.E., Keavery T.M., 2011, Influence of vertical trabecular on the compressive strength of the human vertebra, Journal of Bone and Mineral Research, 26(2): 263-269. DOI: 10.1002/j bmr.2007

[15] Mosekilde L, 1988, Age-related changes in vertebral trabecular bone architecture-assessed by a new method, J Bone 1998; 9; 247-50. 